\title{
Uptake of Organisational Work-Life Balance Opportunities: The Context of Support
}

This research examines the relationship between structural and cultural dimensions affecting managerial decision-making about work-life balance opportunities. Through a top-down study of two contrasting Irish organisations, we identify how each of five dimensions of work-life culture: 'managerial and organisational support', 'organisational time expectations', 'career consequences', 'gendered perception of policy use' and 'co-worker support' are mediated through managers to affect availability and uptake of work-life balance opportunities and creating gaps between policy and practice. This study demonstrates how marked distinctions between the personal opportunities managers may wish to offer and the discretion available to them arise. Secondly, the concept of organisational work-life culture is advanced by elaborating the "context of support', namely, interdependencies between organisational culture and structure that affect the uptake of work-life balance opportunities. Implications for researchers and practitioners are also discussed.

Keywords: work-life balance; organisational culture; structural arrangements; HR policies; managerial support

\section{Introduction}

Organisational work-life balance (WLB) arrangements are often described as a way for workers to maintain a healthy balance between the demands of paid work and their personal life outside. Organisations implement these programmes because of their potential to improve employee commitment and retention (Allen et al. 2003) and productivity (Lewis 1997, 2001; Russell et al. 2009). However, managers have a 
mediating role and uptake of opportunities can remain at low levels even where opportunities exist.

Research into WLB opportunities distinguishes between structural and cultural dimensions (Behson 2005:488). Structural WLB dimensions include any formal HR policy or practice that provides an employee with the flexibility to better combine workplace demands with their personal life (such as flexitime or on-site childcare) and cultural dimensions are informal elements that operate, often below the surface of the organisational context, such as managerial support (Thompson et al. 1999) and coworker support (Breaugh \& Frye 2008; de Sivatte \& Guadamillas 2012), cultural dimensions can also create informal forms of flexibility (such as ad hoc or short-term adjustments to working practice e.g. changes to start and finish times).

Although early WLB research emphasized the benefits of formal HR policies, this focus has shifted in recent years towards examination of the influence of work-life culture on uptake McDonald et al. 2005; Thompson et al. 1999). However, with few exceptions (see for example, Lewis 1997, 2001; Dikkers et al. 2007; Breaugh \& Frye 2008; Aryee et al. 2013; de Sivatte \& Guadamillas 2012) a lack of integration of structural and cultural streams of WLB research has been noted (Hammer et al. 2009; Kossek et al. 2010; Ollier-Malaterre, 2010; Hammer et al. 2011; Greenhaus and Powell 2012). Therefore research has yet to fully theoretically and empirically explore how structural and cultural dimensions interact to affect uptake of WLB opportunities.

We argue that interactions between cultural and structural dimensions are important. Accordingly, we present two qualitative case-studies of Irish organisations with 
contrasting levels of WLB uptake to examine cultural and structural dimensions in context. By focusing on the views of different levels of management within these organisations, we are able to demonstrate how formal and informal WLB opportunities are translated and enacted. We, therefore, extend the debate, both empirically and theoretically towards an intra-organizational contextual understanding of how specific elements of work-life culture function within contrasting organisational settings. The paper illustrates how structural and cultural dimensions of WLB are interdependent; each creating a context within which the other might function.

The paper is structured in the following way. We begin with an outline of the literature on structural arrangements for WLB before consolidating the literature on various dimensions of work-life culture. Second, we present the methodology underpinning the research and the findings for both case sites. Finally, we elaborate the notion of 'context of support' and discuss the implications of the study for future research.

\section{Structural Arrangements for Work-Life Balance}

Historically organisational policies and practices have been termed work-life balance when they seek to facilitate the balance between work and an employee's personal life. Here we draw upon a situational definition of work-life balance (Lewis 1997, 2001), concerned with subjective notions like 'keeping the balance' as opposed to a time-based definition concerned with equality of time use Reiter 2007. Equally, the term 'work-life' (Cegarra-Leiva et al. 2012) is deliberately used here in place of 'work-family' (Lewis 1997, 2001; Breaugh \& Frye 2008; de Sivatte \& Guadamillas 2012) to include policies that reach beyond the immediate demands of family. 
Structural arrangements can take the form of policies, programmes or initiatives made available through either statute or private initiative. States institute a number of minimum and statutory offers (including parental and maternity leaves). Internally, organisations can choose to 'top up' these arrangements by extending the length or payment for leave as well as by choosing to offer additional institutional arrangements which have commonly been classified into four broad categories: flexible working arrangements, childcare opportunities, leave arrangements, and support and wellbeing programmes for an extensive global review of policies see Moss 2014). The availability of structural WLB opportunities can vary significantly between organisations within and across countries. There are few cross-national studies but differences have been noted. For example South Korea has limited WLB opportunities (Aryee et al. 2013) in comparison to European countries and differences have been noted between provision in Spain (de Sivatte \& Guadamillas 2012), the UK (Lewis 2001), Turkey (Burke et al 2006) and the US (Breaugh \& Frye 2008).

Uneven adoption of WLB opportunities have been noted between industry sectors, for example, public sector organisations generally offers more formal WLB opportunities than private sector organisations (Francis \& Lingard 2004; Hyman \& Summers 2004).

The benefits of WLB opportunities include the potential for increased employee commitment and retention (Allen et al. 2003) and productivity (Lewis 1997, 2001; Russell et al. 2009). However, it has been argued that research needs to be more sensitive to context, relationships and history (Özbiglin et al. 2011) not least because cultural aspects of organisational functioning have been shown to affect uptake of structural WLB opportunities. 


\section{Work-life culture}

Employee perceptions of positive work-life culture have been linked to improved job satisfaction and reduced intention to leave (Beauregard \& Henry 2009) and to workfamily outcomes such as reduced conflict and improved wellbeing (Allard et al. 2011) and improved well-being and employee commitment Grandey et al. 2007, Lapierre et

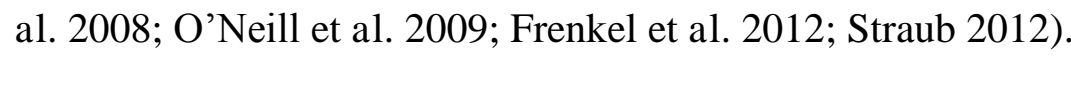

However, studies of organisations with positive work-life cultures argue that, while policies may exist within organisations, staff may hesitate to take part if they perceive a lack of support towards balancing working lives with personal demands Thiede \& Ganster 1995; Lewis 1997, 2001; Thompson et al. 1999). Whilst there remains a lack of conceptual clarity, work-life culture - also known as work-family culture (Behson 2005; de Sivatte \& Guadamillas, 2012; Mauno et al. 2005) or work-home culture (Dikkers et al.2007) - is coalescing around a coherent set of cultural dimensions. These dimensions of work-life culture are thought to affect the rate of WLB uptake. The concept of work-life culture has progressed rapidly since Thompson et al's (1999) proposal of three important additional determinants of WLB uptake: 1.

Managerial and organisational support (sensitivity and willingness of managers for WLB opportunities), 2. Organisational time expectations (perceived demands for workers spend long hours visibly present) and 3. Career consequences (perceptions of negative career outcomes when WLB arrangements are used). Additional components include; 4. Gendered perception of policy use (the pervasive idea that WLB opportunities apply only to women) (McDonald et al 2005 and 5. Co-worker support (the perceived support of colleagues). 
1. Managerial and organisational support

An employee may be reluctant to take up or ask for desired support if they perceive either their supervisor or their organisation to be unsupportive (Dikkers et al 2007). Organisational support for WLB uptake can operate at a proximal level (support from immediate supervisor) and distal level (organisational level e.g. effective communication about availability of formal WLB opportunities, support from senior/HR managers) (McCarthy et al 2012). An argument has been made to distinguish between organisational and managerial support because employees may find their supervisor supportive and the organisation unsupportive (or vice versa) (Allen 2001; McCarthy 2012). We retain the two aspects together to avoid any confusion with the notion of perceived organisational support which incorporates structural dimensions of WLB (McCarthy et al 2012:1257). However, the level of support (managerial and/or organisational) will become important later in the paper.

Thompson et al. 1999,417) defined managerial support as 'the extent to which managers were supportive and sensitive to employees' family responsibilities'. When managers are supportive, employees consistently report a good work-life balance level and higher take-up of organisational opportunities Thiede and Ganster 1995; Bond and Wise 2003. Managerial support is consistently presented as the most important factor in promoting work-life balance for employees (Breaugh \& Frye 2007, 2008). Moreover, Hammer et al. 2009 expand managerial support to encompass four dimensions. This division focuses on the perception that ones' needs can be met though emotional support - where managers talk to workers and are aware of their family and personal commitments - and instrumental support where managers interpret policies and practices in a way that responds to an individual 
employee's work and family needs such as scheduling requests for flexibility.

Additional supports can come when managers demonstrate how to integrate work and family through role modelling behaviours or when they exhibit creative work-family management by strategically and innovatively restructuring work to facilitate employee effectiveness on and off the job.

\section{Organisational time expectations}

Organisations have specific expectations about working hours including the number of hours employees are expected to work and whether they are expected to take work home with them. For example, commitment may be demonstrated by working long hours and presenteeism was linked to greater difficulty in balancing non-work activities Thompson et al. 1999. Productivity-driven cultures foster greater time use flexibility and allow employees a chance to temporally balance work and non-work demands. Therefore, organisational time expectations have been linked to WLB and uptake of opportunities (Lewis 1997, 2001; McDonald et al. 2005.

\section{Career consequences}

The third dimension of work-life culture is negative career consequences associated with uptake of WLB opportunities (Dikkers et al 2007). For example, employees may forsake opportunities for fear of signalling prioritisation of family life over the demands of work. Indeed, this behavioural divergence has been linked to negative career consequences Drew et al. 2003. Part-time workers are offered fewer training opportunities and part-time work has been said to be incompatible with either career advancement or certain high status occupations Kirby \& Krone 2002. As a result, employees may be reluctant to take up WLB opportunities. 


\section{Gendered Perception of Policy Use}

WLB opportunities are used almost exclusively by working women with caregiving responsibilities. This one-sided take up suggests that policies are understood along gendered lines (Lewis 1997; Burke et al 2006). When an assumption exists that these policies are designed to support women in the workplace, men hesitate to make use of them McDonald et al. 2007). Consequently, when men do break these cultural norms, research suggests they face even greater potential career costs Lewis and Campbell 2008.

\section{Co-worker support}

The final dimension affecting take-up of policies is the overall supportiveness of coworkers. When organisational policies provide, or are perceived to provide, more opportunities for one group than another a backlash can occur. This is particularly common in two circumstances; where those who remain have to take on extra work and where they are unable to take up similar opportunities Young 1999, Hegtvedt et al. 2002 Daverth 2011. Thus, when employees perceive resentment from their coworkers they may be less likely to take up opportunities.

In summary, these five elements have been used to delineate how work-life culture affects uptake of WLB opportunities. We draw upon these cultural dimensions in the following study. The principal research objective of this paper is to examine how structural WLB supports and work-life culture influences managerial decisionmaking. 


\section{Methodology}

Informed by an interpretivist approach, we examined how structural WLB opportunities affect managerial decision-making through in-depth case studies at two large organisations in Ireland using dimensions of work-life culture as a lens. The first (Organisation A), was a private manufacturing firm employing over 5,000 people and the second (Organisation B), was a public utility employing over 10,000 people. They were purposely selected for their contrasting WLB policies. Organisation A operated in a historically male-dominated field with a reputation for being less familyfriendly while Organisation B, also male-dominated, was self-described as a progressive employer in respect of WLB policies. These differences presented valuable opportunities to examine how organisational work-life culture and structural arrangements for WLB interact in two contrasting organisations.

Both organisations were based in Dublin with operations across Ireland - an EU member state and subject to EU Directives on statutory support including maternity and parental leave minimums. Yet unlike some other EU countries, Ireland has no mandate for supplementary WLB opportunities and no statutory rights for paternity leave or flexible working arrangements. Over the past two decades, Ireland has also had a unique labour market landscape, first marked by a period of rapid growth where total unemployment dropped from 18 per cent in the late 1980 's to a low of 4.5 per cent in 2007 just prior to this study. The most striking growth in employment levels was women's labour market participation with total employment increasing from 37 per cent in 1993 to 60.5 per cent in 2008 (CSO, 2004, 2008). Culturally, these labour market changes have been linked to major social changes which transformed traditional household arrangements Redmond et al. 2006. Organisational case 
studies were conducted against this cultural backdrop immediately prior to the global recession with interviews conducted between January and February 2008. Unemployment was less than 5\% and the need to retain employees brought WLB to the fore.

The data presented here arises from 30 semi-structured interviews with middle and senior managers. It was informed by a broader organisational case study methodology that included examination of policies, informal conversations with members of HR, and a survey of staff. The interviews were 90-120 minutes long and were held on-site in private offices and meeting rooms. Managers were selected in hierarchical triad groupings including an Executive Director at each organisation, 5 senior managers who report to the Executive Directors and the remainder comprising multiple middle managers who reported to one of the senior managers interviewed. This design provided a multi-tier organisational perspective which allowed for a rich understanding of WLB uptake in context.

Overall, thirty managers were interviewed -15 at each firm. This constituted a stratified quota sample and managers were selected using a non-random purposive technique -21 male, 9 female (See Table 1). Managers were chosen under the guidance of the Executive HR Directors with the aim of representing individual differences and variations across organisational branches as well as pinpointing senior-middle manager dyads that might exhibit extremes - high or low levels of WLB - and capture a few special teams to the extent that they had unusual programmes or working conditions. In terms of gender distribution, given the small pool of female managers, there was an oversampling of female managers at both 
organisations. In terms of gender equality, less than $10 \%$ of the management chain at organisation A were women and just prior to the study they had appointed their first female manager to a senior level. Organisation B had significantly broader female management permeation with most at middle management levels (although managers oversaw much smaller groups than their cohorts at organisation A). At senior levels, organisation B also had a few women in the female dominated areas (such as marketing and customer service).

(Insert Table 1)

The decision-making process about how and when to make use of structural WLB opportunities was examined through a semi-structured interview protocol that examined the five dimensions of WLB culture; managerial and organisational support, organisational time expectations, career consequences, gendered perception of policy use and co-worker support. A template analysis based on how the structural opportunities played out according to the five cultural themes was employed to analyse the data King 2004. Once the interviews had been transcribed, extracts were coded into these broad themes with the help of the software package N-Vivo.

Additionally, further themes were added to the template as they emerged. This revision of coding allowed for templates to be structured flexibly in response to emergent themes Nadin and Cassell 2004. Each of the five anticipated themes had a number of sub-themes. For example, within 'managerial and organisational support' there were sub-themes - organisational supports and managerial supports which were again sub-divided into lower-order themes such as views about managing and views about being managed. Once the coding was complete, transcripts were read again in detail and each extract was examined in the context of the transcript to guard against 
fragmentation. The findings reported here arise from careful consideration of the patterns within each of the template themes. Interview quotes are identified in the text by organisation (A or B), the manager's position (SM senior manager or MM middle manager) and gender ( $\mathrm{M}$ male or $\mathrm{F}$ female). We now turn to those findings which are presented for each case site and follow the five dimensions of work-life culture after a brief case outline.

\section{Managerial decision-making about WLB opportunities - Organisation A}

Organisation A was a large private manufacturing firm organised into two large divisions with distribution centres throughout Ireland. Data was collected across one of these divisions. It was a male-dominated firm with pockets of female employment found in specialised areas such as the call centre, human resources and marketing departments, as well as in various supporting roles. Within the management chain, less than $10 \%$ of middle managers were women. In the months prior to this project, the organisation had appointed its' first woman to a senior position.

Given these facts it was perhaps unsurprising to find very few examples of staff taking up WLB opportunities including statutory arrangements. Senior managers explained that there was little need for such programmes and went on to note a stigma attached to those who took up WLB opportunities; "I would say that people still think it's a little bit funny, but it's a little bit more acceptable and understandable to a void major traffic times and stuff like that" (A:SM:M). The middle managers in the organisation further expanded this view in unanimously agreeing that non-traditional working was both rare and inconsistent. 
Managerial and organisational support

Managers had little knowledge of the WLB opportunities in place indicating a lack of organisational support. This lack of support was described by one middle manager; "I know that if I asked for unpaid leave, for parental leave, which I'm entitled to, I'd have to struggle to get that" (A:MM:M). Managers suggested that the organisation had no interest or obligation towards employees' personal lives with one manager saying; "I wouldn't say my boss has a concern about whether I balance my work and my life" (A:MM:F). Indeed, many middle managers experienced no support or acknowledgement of WLB needs. In this respect, one manager reported; "I'm not encouraged by the organisation or peers," (A:SM:M) and "it's what I do myself to make it happen" (A:SM:M).

Managers reported an overall lack of concern for work-life balance levels across the organisation coupled with little guidance or encouragement on how to support their staff. Managers described a reactive work-life balance culture pointing to the lack of structural HR policies or communication. The HR manager described WLB as resting at the sole "discretion of managers" in their respective departments but added that "it wouldn't be at the top of their agenda" (A:SM:M). This lack of support for WLB was noted by other managers; "I would like to have more life than work. I do have freedom of autonomy to have WLB to a degree, but the pressure is there not to have it (A:MM:F).

There was considerable confusion among all managers about the availability of structural WLB opportunities. Formally, organisation A offered only leave as required by law, yet managers at all levels were unable to describe these 
arrangements, whether they were available or how one might find out about them. While the Executive Director, Director and senior manager in the HR department expressed certainty that a formal document existed, they were unaware of the particulars and more specifically where this information was located or how it would be communicated to staff. Only the line manager in the HR department knew where the information was located;

The main ones would be maternity leave, parental leave, force majeure leave, we have a carer's leave policy as well [all mandated]. They are all developed by HR, managed by HR, and listed in the HR policy and procedures manual and that is given out to managers within the organisation. Fifty per cent of current managers have it but there may be some new managers, who wouldn't have it. They might not know if it exists and we are trying to get that to them so they would know when situations arise. That's the main source of information (A:MM:F).

However, her view that about half the managers knew of the policy appeared to be overly optimistic. Almost all managers were unaware "[the policies] don't exist" (A:SM:M); "I would think we have no policies here ... I would ask HR" (A:MM:M). Indeed, only one manager had knowledge of the HR manual though he reported that, while "there is a hard copy," in terms of policy descriptions, "I really can't understand them" (A:MM:M). Managers suggested that "there isn't really any worklife balance communication" and that if questions arose staff seek information directly from their managers who would then attempt to find the answers from HR; "you'd have to approach HR and query it with them" (A:MM:M). These comments exemplify the reactive stance found across the organisation in relation to WLB. Managers understood that they would be the first point of contact but were unaware of what was available. "Where there is a legal obligation we have a healthy attitude to it but to the others we don't' (A:SM:M). 
Organisation A had a decentralised HR structure with line managers being the point of contact for staff interested in taking up structural WLB opportunities. Managers' responses to WLB requests from their staff varied and when WLB arrangements were made they were informal and considered to be exceptional. Managers almost universally feared being barraged by staff requests should initiatives be offered or widely communicated (a few said they were concerned about the repercussions of simply participating in this research). Managers were not told how to deal with staff requests though they reported general discouragement for flexibility and WLB opportunities. Moreover, the particular lack of WLB policies, communication or training for dealing with staff left managers having to rely upon their own interpretation of cultural expectations about how flexible they should be. "It's never been discussed ... I can only speak for myself and with my own guys, I would always actively seek out a guy that's struggling, time-management is something I would look at with him" (A:MM:M).

When deciding how to support their staff, managers explained the norm was to manage their respective departments based on how they saw the senior level managers operating their own; "I would be open to consider a flexi-time in my department, but I would wait for the encouragement to come from the top. It's got to come from the top down" (A:MM:F). In other words, in the absence of support or precedent from the top, these managers felt risk in deviating from the norm. This is important because middle managers attempted to anticipate senior managerial attitudes; "in my personal opinion it comes from the hierarchy, they're your boss so you're worried about their attitude" (A:MM:M). One simple example was given by a middle manager who was 
denied the opportunity to work from home one day a week; "[the senior manager] didn't feel like I could handle the situation from home. It's a trust thing, if you're not here there's a feeling you're not working” (A:MM:M). Indeed, as a result, this manager went on to mention repeatedly the need to watch his staff and ensure they actually were where they claimed to be. Other managers also interpreted WLB as an issue of trust, this held true for both male and female managers.

Organisational time expectations

My own opinion is the job has to be done and if it goes into your social or after work life so be it ... when you're given a task to do, you do it. Time-management, that's a good key word (A:MM:M).

In a broader sense, managers described the WLB culture in terms of presenteeism and "getting on with the work" (A:MM:M) and individuals spoke in terms of universal tacit agreement to these principles;

We all tend to have the same attitude toward WLB, we all know what our job is and we can work within that criteria and still get a day's work done and go home yet still have a home life at the end of the day. (A:MM:M).

The implication of these perspectives suggests that the pursuit of a 'private life' was antithetical to the organisational culture. This finding held true at managerial levels, "because managers are expected to work every hour that the business needs, make a sacrifice" (A:MM:F). In other words, to move up the corporate ladder an employee had to sacrifice home life. This translated to people working long hours; "I would think most of us work late. We would have long days - early starts and six o'clock finishes also working weekends although we would try to avoid it" (A:SM:M). Yet for more senior positions this culture was even greater; "we need a director here. My job and most directors jobs are seven days a week" (A:SM:M). There was a very strong 
unified picture of the organisational time expectation although not all managers reported being in agreement with these principles particularly those at middle management levels.

\section{Career consequences}

If they stop working then their career stops ... If I'm off on maternity leave I can't be working and if I'm not working, I can't get experience and if I have three children that's a good bit of experience I'm losing. I haven't got the same experience that they would see from someone the same age at the same point in their career, that's the facts (A:SM:M).

This male manager described the 'clear' career consequences, for women at this organisation of taking up WLB opportunities. A fear was reported that seeking WLB arrangements would damage one's career; “people just don't like speaking up on things that might damage their careers" (A:MM:F). Reason to fear reprisal was evident throughout the interviews; "It depends very much on the potential of the individual but it wouldn't be in that person's favour" (A:SM:M). Managers viewed arrangements with suspicion and those who took up statutory provisions were penalised in terms of their career progression. The HR director justified this by arguing that in a male-dominated organisation, individuals were judged on the amount of time they put into their careers. In other words, promotions were based on loyalty and commitment which was evaluated in terms of time on-site.

Gendered view of policies

Another striking theme was a gendered understanding of WLB. "I think the family situation very much becomes a female issue" (A:SM:M). Managers related this to the gendered division of labour, "I believe that females take their domestic life differently. Say women work nine to five, the males work longer hours, females have more of a 
domestic role than the husband" (A:SM:M). Women who remained in the workforce after marriage (and particularly after having children) struggled to "hold down two jobs" (A:SM:M). Particularly at senior levels, there remained an explicit belief that women's labour market role was secondary to family and no amount of organisational support could change that. As the executive HR director noted, women "just wanted to stay home with the children regardless of what the organisation offered." He cited a manager who was offered the opportunity for flexible working to her own timetable on return from maternity leave; "Even that wouldn't do it for her. It just wasn't working; she wanted to be home with the kids. That was her priority and that was her decision. It's kind of a mixed bag of it" (A: SM:M). He argued that structural supports fail to address women's priorities - the desire to remain at home. This was in stark contrast to work-life culture in the second organisation.

\section{Co-worker support}

Although rare, when individuals did take up WLB opportunities resentment was reported. Managers reported maternity leave specifically as being a strongly divisive issue, "I think that there is a little bit of resentment because she is going on maternity leave and she is getting off a bit and I'm not - I'm stuck here doing this and there is no appreciation for the person who isn't going on maternity leave" (A:MM:F). Many managers reported this resentment as partially linked to an unfair workload redistribution caused by the employee's absence;

Because [maternity leave] has gotten so long now, people who are left behind feel like companies don't often replace the person who's gone and what's left is three or four people in the department to pick up the work. So if you have three people pregnant one after another in a department where they can't be replaced, you're left with one person 
who is actually working there. People can get very resentful, very unhappy about it (A:SM:M).

When other examples were given of staff who managed to negotiate non-statutory work arrangements they were reported as "inconsistent [and varying] from manager to manager and director to director" (A:SM:M), and access to such flexibilities was related to individual circumstances. As a consequence, staff reported resenting the secrecy and unequal distribution. In one example, a department had arranged for staff to come in early a few days a week and take one Friday off each month. Managers in other departments resented this because it was set up behind closed doors, operated in secret and they were unable to make similar concessions for their own staff.

\section{Managerial descision-making about WLB opportunities - Organisation B}

"We have a very progressive suite of policies and procedures in place, and senior managers are very aware of the need for people nowadays to have the facility to avail of life-work balance initiatives" (B:SM:M).

Organisation B was a large public utility with multiple divisions and centres throughout Ireland. Data was collected across two divisions - a front-office femaledominated division and a back-office male-dominated division. Organisation B had a higher permeation of women into senior levels, although there were no female managers at the highest level. The HR executive director described Organisation B as one of the best in Ireland in terms of offering work-life balance supports.

In recent years, the organisation had increased the structural work-life provisions to include traditional options (flexible working, job-sharing, career breaks) as well as a number of rather progressive measures (annualised hours, travel breaks, social and 
wellness groups which encouraged physical activity). Additionally, senior managers reported purposeful creation of a positive discourse about WLB opportunities and a positive environment. These efforts were coupled with a terminological shift towards gender-neutral terms; "I like to call it life-work balance so that life come first!" (B:SM:M).

At this organisation, the managers outlined a more nuanced approach to WLB, trying to promote uptake while noting the impact of uptake for their departments. Each manager had first-hand experience of employees seeking and taking up WLB opportunities. Indeed, many of the managers had taken advantage of the programmes too.

Managerial and organisational support

Organisational support was indicated by the fact that WLB opportunities were communicated widely across the organisation; "we all know about them" (B:MM:F). Indeed, unlike organisation A, managers were confident that their staff knew about WLB opportunities. While the Executive HR director had difficulty in describing the particulars of policy, unlike his counterparts at Organisation A, he went on to describe the myriad of communication channels open to the staff concluding that staff "should have no difficulties accessing what's available" (B:SM:M). This was echoed by managers across the organisation. Whereas the majority of managers at Organisation A were uncertain about what legal entitlements their staff had, the managers in Organisation B were notified through team briefings, an intranet system, and supported by a strong proactive HR division. Information was freely available to all staff about WLB opportunities. 
I would say that our organisation is ahead of most other companies. I know companies where people have gone to their bosses and said I just want to ... and were told to just turn around and run out the door - if you don't like it here just clear out. We don't do that. This organisation is not only reactive to people but is being more proactive in terms of trying to have policies that would be ahead of most companies (B:SM:M).

Managers were also able to articulate organisational expectations about how to manage WLB in their division;

We understand that there are times when people have stresses in their lives and time demands. Most managers would be flexible in the confines of the job (B:SM:M).

Universally, managers reported that they felt an obligation to be "proactive [and] offer flexibility” (B:SM:M). Although managers felt the proactive stance of the organisation undermined their authority at times, there appeared to be a shared understanding about the espoused values of the organisation in relation to work-life balance.

Not all managers were in agreement with these principles, nevertheless, most managers described having had positive experiences. This included descriptions about how the actions of supervisors had positively influenced their own work practices;

My boss is incredibly supportive and would say - look, it's five thirty, it's time to go home, and why are you staying here late? Or, if you have any problem with the kids just give me a buzz. So I would find him incredibly supportive. That's far more important in many ways than organisation policy or what's written down (B:SM:M). 
These managers reported general support and encouragement from their managers in terms of WLB. Likewise, managers reported shared understanding of the organisational structural supports and culture in relation to managing their departments, "There would certainly be an attitude that, where I can, to be flexible" (B:MM:F).

\section{Organisational time expectations}

While managers argued that their performance was judged more in terms of output and productivity than the amount of time spent in the office; "we're given the freedom to do the job and we're not asked in any specific way to account for our time" (B:SM:M). They also reported that this view didn't reduce long hours and there was a general feeling that workload pressures were on the rise; "The workload had been very high the last five years, so it has put pressure on people to work a lot of overtime or extra hours" (B:MM:F). Increasing pressure was reported at all levels but it was middle managers who reported the greatest pressures to get the work done. "You'd be working 8.15 to 9.00 every night and some part of every weekend... That would not be unusual" (B:MM:M).

While there was an emphasis on WLB, ultimately there was still an expectation to prioritise work;

I think the organisation adopts WLB principles. I think individuals within the management team will adopt this because, in my own case, I feel strongly about it ... But, when push comes to shove, the organisation expects you to be there... There's quite a reasonable balance, but I have been involved in a lot of projects now and there is a 
clear expectation that the organisation's objectives and deliverables are central (B:MM:F).

\section{Career consequences}

However, managers acknowledged that take-up of structural supports came with a cost and some felt there was an associated stigma;

"Where it might count against people to some degree might be in areas such as promotion. Managers, maybe individually or collectively, would have a view that there are certain positions that aren't amenable to somebody working on a part-time basis or job sharing” (B:SM:M).

Some managers linked the career cost to organisational time expectations insofar as people who were working half time were competing with individuals who were putting in very long hours.

"You have people who are putting in 70 hours a week saying why shouldn't I get the recognition for it, so it's a little bit of a double edged sword, but it's definitely a factor" (B:MM:F).

So although managers had positive views of WLB at Organisation B there was a continued association between perceived commitment, career potential and an employee's time on-site. In other words, those who were physically present at higher levels deserved recognition and reward for their dedication through promotion.

Gendered view of policies

The attitudes in Ireland and in our organisation are probably still that it's the women who take the majority of leave. That puts a particular burden on them and those childbearing years (B:SM:M).

In spite of the terminological shift from 'family-friendly' to 'work-life', managers saw WLB largely through a gendered lens and predominantly an issue for mothers. 
While every manager across the organisation understood the company commitment to accommodating requests from mothers (and carers), there were no accommodations available for other activities.

In general, the policy of the organisation would be not to refuse people who were looking for reduced hours for family reasons, but if they wanted to work 3 days because they wanted to improve their golf or whatever we would take a different view (B:SM:M).

Co-worker support

I think that there is resentment where somebody maybe would like to have taken advantage of reduced hours and, for business reasons, they weren't able to. They are bound to feel that 'I am here carrying the can"” (B:SM:M).

In theory, opportunities were available to all but in practice this was not the case. There were certain jobs that were incompatible with part-time working for example and therefore employees were unable to take up a desired programme - particularly at management levels. This was reported as divisive among staff leaving a "very real" feeling of injustice by those not availing of WLB leave and flexibilities.

Furthermore, managers were unhappy about their lack of decision-making authority. There were a number of examples of poorly constructed accommodations being made without consulting the line manager. This included people job-sharing alone and individuals who were not replaced when on leave, resulting in a departmental deficit. Accordingly, middle managers reported “...it's us that are actually the ones who are paying the price for others having reduced hours" (B:SM:M).

\section{Contrasting organisations A and B}


In summary, both organisations conformed to type, as the public sector organisation (B) offered more WLB structural supports than the private sector case study (A) (Hyman \& Summers 2004). Both organisations had distinct WLB opportunities and work-life cultures - these differences had interesting consequences. At Organisation $\mathrm{B}$, whilst the organisation and managers maintained a structural and cultural commitment to supporting individuals in their care-giving roles, many (particularly middle managers) perceived a lack of control over those decisions. Managers also reported a tendency to over-burden those who were not taking advantage of such opportunities, not least the managers themselves, which led to resentments. In contrast, the reactive environment of Organisation A, left managers (particularly at senior levels) with a high level of discretion to offer informal arrangements that suited their business needs and they could unilaterally reward good behaviour and encourage staff loyalty. Yet a lack of structural opportunities meant there were few examples of WLB uptake in practice and managers themselves suffered from greater work-life imbalances alongside pressure to prioritise work over home life for both themselves and their staff.

\section{Organisational Context of Support}

The findings both support and expand upon previous attempts to understand the effects of organisational work-life cultures on managerial decision-making about WLB arrangements (Lewis 200; Dikkers et al 2007). In particular, our first contribution lies in demonstrating interdependencies between structural arrangements for WLB opportunities and organisational work-life culture that affect WLB uptake in practice - 'the context of support'. The two case studies exhibit remarkably different structural and cultural approaches to WLB opportunities and the high degree of 
agreement between managers at each organisation illustrates the level to which they were aware of the structural arrangements for WLB. More importantly, they illuminate the manner in which this understanding constrains the ability to respond to WLB needs. It might be argued that the high level of agreement between managers could be accounted for by attraction-selection-attrition theory (Law 2009) whereby individuals are attracted to and selected by organisations whose members resemble themselves and those who do not fit will leave over time. Therefore the personality traits of those working for an organisation become more similar over time. However, this concept (person-organisation fit) conflates several subsets such as; personsupervisor fit and person-job fit (Ostroff \& Schulte 2007) and both organisations offered examples of managers who disagreed with the WLB 'ethos' of their organisation, yet the managers felt compelled to anticipate and mirror what the organisation and, more specifically, their senior managers would want in a given situation.

Attention to the effects of managerial role modelling behaviour has been called for in recent research (de Sivatte \& Guadamillas 2012). We found that managers took cues from both the structural availability of opportunities and work-life cultural dimensions specific to their organisation - particularly in relation to mirroring the behaviour of senior managers. When deciding how to deal with work-life balance requests, middle managers made decisions in keeping with their perceptions of senior management expectations. There was a marked distinction between the personal supports a manager might wish to offer and the discretion they felt was available to them. This finding held true across gender lines. 
The interaction between organisational and managerial support meant that, in the absence of organisational support managers looked to their seniors for indications of how to respond. The minimal structural supports and limited examples of WLB among senior managers at Organisation A meant managers kept uptake of WLB opportunities to a minimum. Even statutory opportunities were actively discouraged and stigmatised. Counterintuitively, managers simultaneously had a high level of freedom to offer one-off informal WLB opportunities. However, rather than using this discretion to encourage WLB, these opportunities formed rewards for good behaviour with the aim of encouraging loyalty. In contrast, Organisation B offered a wide array of structural WLB arrangements and senior managers exhibited a healthy work-life balance (or at least an attempt to achieve one) coupled with active encouragement for middle managers to do the same, particularly those with caregiving roles.

This empirical account of the interactions between structural and cultural dimensions of WLB builds on previous work in this area (Breaugh \& Frye 2008) and highlights the potential of in-depth examinations of contexts of organisational support. Specifically, when managers are interpreting WLB needs within their departments they draw upon a deep understanding of their organisation in deciding how to act. This includes a nuanced understanding of the structural opportunities (or lack thereof) and their interpretation of cultural expectations about how supportive they should be. Accordingly, this indicates the need for more research focusing on managerial decision-making about WLB opportunities to use perspectives that articulate different aspects of context. The implications of this expanded focus may illuminate a more nuanced understanding of managerial decision-making in work-life balance research. 
The second contribution extends this theoretical 'context of support' to develop a deeper understanding of the interdependencies and specifically how structural differences directly affect the way in which the empirically developed work-life culture dimensions function. In other words, the five dimensions of work-life culture \begin{tabular}{|l|l|l|l|l|l|}
\hline Thompson et al. 1999, Allen 2001, McDonald et al. 2005 function differently & \\
\hline
\end{tabular} depending on the organisational structural context. While previous research has focused on the two domains separately, this study illustrates how attention to both can alter the way we understand both managerial decision-making and WLB uptake and open up new avenues for research.

To elaborate on these interdependencies in the context of Organisation B, the wide communication of structural HR policies influenced the informal culture where managers and staff were aware of the content and ethos of the formal policies to support caregivers. General knowledge about WLB policies meant that managers experienced pressure to support staff uptake Ryan \& Kossek 2008. Yet in contrast, Organisation A illustrates the development of a work-life culture in the absence of structural arrangements where informal arrangements become more influential. In other words, in the absence of structural guidance, middle managers attempted to anticipate the views of senior managers in decision-making thus recreating the dominant organisational work-life cultural norms.

We have detailed interactions between two arguably distinct elements; managerial and organisational support McCarthy et al. 2010; 2012). Managers who perceived a lack of organisational WLB opportunities described not being able to achieve a healthy personal WLB or to be able to support WLB opportunities for their staff through 
formal or informal channels. At both organisations, it was apparent that managers formed their understanding of the work-life culture by taking cues from senior managers. This suggests a classic virtuous/vicious circle scenario - managers who experience a supportive culture are able to take up WLB opportunities thus displaying behaviours they interpret as reflecting this culture. Yet when cultural supports were not available, managers were unable to model alternative behaviours. Consequently, managerial role-modelling and the ability to encourage WLB appears connected to perceptions of organisational support - a finding that has important implications. While recent research highlights the importance of examining these two elements distinctly (Allen 2001; McCarthy 2012), we suggest that it is also necessary to examine the relationship between managerial and organisational support.

In extending this link, we were also able to illustrate how structural differences influence the function of cultural dimensions around time expectations. Managers at both organisations reported working long hours and feeling the need to prioritise work, yet this played out very differently between the organisations. Within organisation B, for example, a link was found between the formal non-traditional working options and the cultural time expectation. While managers reported high workloads and pressure they also acknowledged organisational pressure to keep a balance and reference using - and facilitating the use of - structural arrangements to help this process. Furthermore, when managers discussed work-family time management issues, they spoke about workplace supports to reduce conflict such as taking work off their desk or attending a time-management course (Breaugh \& Frye 2008). In contrast, the absence of structural arrangements at Organisation A led many managers to describe balancing work and life as a private matter of no concern to the 
workplace. Interestingly, when work-family time conflict arose at this organisation, managers would try to facilitate time away from work, for example, by giving individuals the afternoon off. In both organisations, even when cultural dimensions may appear similar, important nuances are apparent when cultural dimensions are examined in the context of structural differences offering a further avenue for research, for example, how individual characteristics relate to work-life culture in the decision-making process.

There are wider effects on managerial WLB decision-making. These case studies illustrate how similar cultural outcomes persist despite structural differences particularly in the case of gendered perceptions of WLB policies (McDonald et al 2005). Managers at Organisation A argued that mothers prefer to be at home and that no amount of organisational support could change that while Organisation B encouraged take up by both men and women. It is notable that differences in structural approaches had little influence on gendered views of WLB and, perhaps more importantly, limits to career advancement remained. A further area for future research arises from the fact that both male and female managers at each organisation described similar gendered perceptions of WLB policies yet past research suggests the potential for gender differences relating to gendered life experiences and views of gender roles (Hegtvedt, et al. 2002).

Cultural normative assumptions, such as gendered behaviour roles, are perhaps too pervasive to be overcome by organisational-level initiatives. However, there were notable differences between organisations. For example, managers at Organisation A reported so few actual examples of WLB take up that their perceptions of the 
gendered nature of these policies were linked more to a personal socio-cultural view of gender differences than reflecting actual working behaviours. In contrast, the high level of take up across Organisation B had mitigated some of this gendered phenomenon and allowed managers to form a more nuanced understanding of the issue. There was an almost universal attempt toward 'keeping the balance' across the gender divide.

\section{Conclusions}

This study has examined the relationship between structural WLB opportunities and dimensions of work-life culture as they affect managerial decision-making and hence the uptake of WLB opportunities. This managerial perspective contrasts with a focus on employee perspectives more usual in this type of research. Using work-life culture as a lens, we have detailed the interaction between structural and cultural dimensions and their contextual interdependencies. We have seen how five aspects of work-life culture affect availability and uptake of structural WLB opportunities through managerial decision-making. We see how marked distinctions between opportunities managers would like to offer and the discretion available to them arise.

The concept of work-life culture is advanced by elaborating what we term 'the context of support' - namely interdependencies between WLB structure and work-life culture that affect managerial decision-making and, consequently, WLB uptake. Contrasting case examples illustrated how uptake of opportunities for WLB are influenced, not only by specific policies but also by local organisational cultures.

The results of this study underscore the need for a revision in the articulation of dimensions of work-life culture toward an understanding that is grounded in this 
interdependency. Future research may include simultaneous attention to both structural and cultural dimensions whilst maintaining a sensitivity to interactions between the two elements - when structural supports are in place cultural dimensions affect uptake differently and there is less reliance upon informal WLB arrangements. One promising direction for future inquiry might include further elaboration of how specific structural arrangements (or lack thereof) interact with specific cultural dimensions. It could be the case that certain cultural elements are more sensitive than others to particular structural arrangements - further elaboration would be worthwhile. Finally, normative cultural assumptions, for example about gender roles, play a part in restricting the impact of structural provisions on WLB behaviours and beliefs. We have advanced the concept of organisational work-life culture by elaborating the 'context of support', namely interdependencies between organisational culture and structure that affect managerial decision-making and, as a consequence, WLB uptake. Our contention is that future research cannot treat structural and cultural dimensions of WLB as independent features of organisational functioning.

\section{References}

Allard, K., et al. (2011). "Family-supportive organizational culture and fathers' experiences of work-family conflict in sweden." Gender Work and Organization 18(2): $141-157$.

Allen, D. G., et al. (2003). "The role of perceived organizational support and supportive human resource practices in the turnover process." Journal of Management 29(1): 99-118.

Allen, T. D. (2001). Family-supportive work environments: The role of organizational perceptions. Conference of the Academy-of-Management, Chicago, Illinois. Aryee, S. Chu, C.W.L. Kim, T-Y, Ryu, S. (2013) "Family-supportive work environment and employee work behaviors: An investigation of mediating mechanisms" Journal of Management 39(3): 792-813. 
Beauregard, T.A. Henry, L.C. "Making the link between work-life balance practices and organizational performance" Human Resource Management Review 19: 9-22. Behson, S.J. (2005) "The relative contribution of formal and informal organizational work-family support" Journal of Vocational Behaviour, 6, 487-500.

Breaugh, J.A. Frye, N.K. (2007) "An examination of the antecedents and consequences of the use of family-friendly benefits" Journal of Managerial Issues XIX(1): $35-52$

Breaugh, J.A. Frye, N.K. (2008) "Work-family conflict: The importance of familyfriendly employment practices and family supportive supervisors" Journal of Business Psychology 22: 345-353

Bond, S. and S. Wise (2003). "Family leave policies and devolution to the line." Personnel Review 32(1-2): 58-72.

Burke, R.J. Koyuncu, M. Fiksenbaum, L. (2006) "Organisational practices supporting women's career advancement and their satisfaction and well-being in Turkey" Women in Management Review 21(8): 610-624.

Cegarra-Leiva, D. Sanchez-Vidal, E. Cegarra-Navarro, J.G. (2012) "Understanding the link between work life balance practices and organisational outcomes in SMEs: The mediating effect of a supportive culture" Personnel Review 41(3): 359-379 Daverth, G. (2011). Revisioning theoretical perspectives in work-life balance Academy of Management San Antonio, Tx

de Sivatte, I. Guadamillas, F. (2012) "The measurement of work-family culture in Spain and some applications to other economies" International Journal of Human Resource Management 23(9): 1930-1949

Moss, P., Ed. (2014). International review of leave policies and related research 2014. Brussels, CBGS

Dikkers, J.S.E. Geurts, S.A.E. Den Dulk, L. Peper, B. Taris, T.W. Kompier, M.A.J. (2007) "Dimensions of work-home culture and their relations with the use of workhome arrangements and work-home interaction" Work and Stress 21(2): 155-172 Drew, E., et al. (2003). Off the treadmill: Achieving work/life balance. Dublin, National Framework Committee for Family Friendly Policies.

Francis, V. Lingard, H. (2004) A quantitative study of work-life experiences in the public and private sectors of the Australian construction industry Brisbane, Construction Industry Institute.

Frenkel, S., et al. (2012). "How employee perceptions of hr policy and practice influence discretionary work effort and co-worker assistance: Evidence from two organizations." The International Journal of Human Resource Management: 1-18. Goodstein, J. D. (1994). "Institutional pressures and strategic responsiveness employer involvement in work family issues." Academy of Management Journal 37(2): 350-382.

Grandey, A. A., et al. (2007). "Work-family supportiveness organizational perceptions: Important for the well-being of male blue-collar hourly workers?" Journal of Vocational Behavior 71(3): 460-478.

Greenhaus, J. H. and G. N. Powell (2012). "The family-relatedness of work decisions: A framework and agenda for theory and research." Journal of Vocational Behavior 80(2): 246-255.

Hammer, L. B., et al. (2011). "Clarifying work-family intervention processes: The roles of work-family conflict and family-supportive supervisor behaviors." Journal of Applied Psychology 96(1): 134-150. 
Hammer, L. B., et al. (2009). "Development and validation of a multidimensional measure of family supportive supervisor behaviors (fssb)." Journal of Management 35(4): 837-856.

Hegtvedt, K. A., et al. (2002). "Reactions to injustice: Factors affecting workers' resentment toward family-friendly policies." Social Psychology Quarterly 65(4): 386400.

Hyman, J. Summers, J. (2004) "Lacking balance?: Work-life employment practices in the modern economy" Personnel Review 33(4): 418-429

King, N. (2004). Using templates in the thematic analysis of texts. Essential guide to qualitative methods in organizational research. C. Cassell and G. Symon. London, Sage.

Kirby, E. L. and K. J. Krone (2002). "'The policy exists but you can't really use it": Communication and the structuration of work-family policies." Journal of Applied Communication Research 30(1): 50-77.

Kossek, E. E., et al. (2010). "Work-life initiatives and organizational change: Overcoming mixed messages to move from the margin to the mainstream." Human Relations 63(1): 3-19.

Lapierre, L. M., et al. (2008). "Family-supportive organization perceptions, multiple dimensions of work-family conflict, and employee satisfaction: A test of model across five samples." Journal of Vocational Behavior 73(1): 92-106.

Law, J. (2009) A dictionary of business and management $\left(5^{\text {th }}\right.$ Ed) Oxford University Press, Oxford.

Lewis, S. (1997) "'Family friendly' employment policies: A route to changing organizational culture or playing about at the margins?" Gender, Work and Organization 4(1): 13-23

Lewis, S. (2001) "Restructuring workplace cultures: the ultimate work-family challenge?" Women in Management Review 16(1): 21-29

Lewis, J. and M. Campbell (2008). "What's in a name? 'Work and family' or 'work and life' balance policies in the uk since 1997 and the implications for the pursuit of gender equality." Social Policy \& Administration 42(5): 524-541.

Masuda, A. D., et al. (2012). "Flexible work arrangements availability and their relationship with work-to-family conflict, job satisfaction, and turnover intentions: A comparison of three country clusters." Applied Psychology-an International ReviewPsychologie Appliquee-Revue Internationale 61(1): 1-29.

Mauno, S. Kinnunen, U. Piitulainen, S. (2005) "Work-family culture in four organizations in Finland" Community, Work and Family 8(2): 115-140

McCarthy, A., et al. (2010). "Work-life balance policy and practice: Understanding line manager attitudes and behaviors." Human Resource Management Review 20(2): 158-167.

McCarthy, A., et al. (2012) "Employee work-life balance outcomes in Ireland: a multilevel investigation of supervisory support and perceived organisational support." International Journal of Human Resource Management24(6): 1257-1276

McDonald, P., et al. (2005). "Organisation work-life culture: Five dimensions proposed." Women in Management Review 20(1): 37-55.

McDonald, P., et al. (2007). "Freedom or fallout in local government? How work-life culture impacts employees using flexible work practices." International Journal of Human Resource Management 18(4): 602-622.

Nadin, S. and C. Cassell (2004). Using data matrices. Essential guide to qualitative methods in organizational research. C. Cassell and G. Symon. London, Sage. 
O’Neill, J. W., et al. (2009). "Work-family climate, organizational commitment, and turnover: Multilevel contagion effects of leaders." Journal of Vocational Behavior 74(1): 18-29.

Ollier-Malaterre, A. (2010). "Contributions of work-life and resilience initiatives to the individual/organization relationship." Human Relations 63(1): 41-62.

Ostroff, C. Schulte, M. (2007) "Multiple perspectives of fit across levels of analysis" In C. Ostroff and T. Judge (Eds) Perspectives on organizational fit Erlbaum, NJ. Özbiglin, M.F. Beauregard, A. Tatli, A. Bell, M.P. (2011) "Work-life, diversity and intersectionality: A critical review and research agenda" International Journal of Management Reviews 13: 177-198

Redmond, J., et al. (2006). Literature review of issues related to work-life balance, workplace culture and maternity/childcare issues. Dublin, Crisis Pregnancy Agency. Reiter, N. (2007). "Work life balance: What do you mean ?: The ethical ideology underpinning appropriate application." The Journal of Applied Behaviorial Science 43(2): 273-294.

Russell, H. O'Connell, P.J. McGinnerty, F. (2009) "The impact of flexible working arrangements on work-life conflict and work pressure in Ireland" Gender, Work and Organisation 16(1): 73-97

Ryan, A. M. and E. E. Kossek (2008). "Work-life policy implementation: Breaking down or creating barriers to inclusiveness?" Human Resource Management 47(2): 295-310.

Russell, H., O'Connell, P. J. and McGinnity, F. (2009), The Impact of Flexible Working Arrangements on Work-life Conflict and Work Pressure in Ireland. Gender, Work \& Organization, 16: 73-97

Straub, C. (2012). "Antecedents and organizational consequences of family supportive supervisor behavior: A multilevel conceptual framework for research." Human Resource Management Review 22(1): 15-26.

Thiede, T. and D. Ganster (1995). "Impact of family supportive work variables on work-family conflict and strain: A control perspective." Journal of Applied Psychology 80(1): 6-15.

Thompson, C. A., et al. (1999). "When work-family benefits are not enough: The influence of work-family culture on benefit utilization, organizational attachment, and work-family conflict." Journal of Vocational Behavior 54(3): 392-415.

Wang, J. and A. Verma (2012). "Explaining organizational responsiveness to worklife balance issues: The role of business strategy and high-performance work systems." Human Resource Management 51(3): 407-432.

Wood, S., et al. (2003). "Family-friendly management in great britain: Testing various perspectives." Indusrial RElations 42(2): 221-250.

Wood, S. J. and L. M. de Menezes (2010). "Family-friendly management, organizational performance and social legitimacy." International Journal of Human Resource Management 21(10): 1575-1597.

Young, M. B. (1999). "Work-family backlash: Begging the question, what's fair?" Annals of the American Academy of Political and Social Science 562: 32-46. 
Table 1 - Sample breakdown

\begin{tabular}{|c|c|c|c|c|}
\hline Org A & Sex & Level & Children & status \\
\hline 1 & Male & Exec Director & Yes & Stay at home full-time \\
\hline 2 & Male & Senior Manager & Yes & Works part-time* \\
\hline 3 & Male & Senior Manager & Yes & Stay at home full-time \\
\hline 4 & Female & Middle Manager & No & Single \\
\hline 5 & Female & Middle manager & No & Single \\
\hline 6 & Male & Middle manager & Yes & Stay at home full-time \\
\hline 7 & Male & Middle manager & No & Works full-time \\
\hline 8 & Male & Middle manager & Yes & Works full-time \\
\hline 9 & Male & Middle manager & Yes & Work part-time \\
\hline 10 & Male & Middle manager & Yes & Stay at home full-time \\
\hline 11 & Male & Middle manager & Yes & Stay at home full-time \\
\hline 12 & Male & Middle manager & No & Works part-time \\
\hline 13 & Male & Middle manager & Yes & Works part-time \\
\hline 14 & Male & Middle manager & Yes & Stay at home full-time \\
\hline 15 & Male & Middle manager & Yes & Works part-time \\
\hline Org B & Sex & Level & Children & $\begin{array}{l}\text { Partners employment } \\
\text { status }\end{array}$ \\
\hline 1 & Male & Exec Director & Yes & Stay at home full-time \\
\hline 2 & Male & Senior Manager & Yes & Works part-time* \\
\hline 3 & Male & Senior Manager & Yes & Works part-time* \\
\hline 4 & Male & Senior Manager & Yes & Widowed \\
\hline 5 & Female & Middle manager & Yes & Works full-time \\
\hline 6 & Female & Middle manager & No & Single \\
\hline 7 & Female & Middle manager & Yes & Works part-time \\
\hline 8 & Female & Middle manager & No & Works full-time \\
\hline 9 & Female & Middle manager & Yes & Works part-time \\
\hline 10 & Female & Middle manager & Yes & Works full-time \\
\hline 11 & Female & Middle manager & Yes & Works full-time \\
\hline 12 & Male & Middle manager & Yes & Stay at home full-time \\
\hline 13 & Male & Middle manager & No & Single \\
\hline 14 & Male & Middle manager & Yes & Stay at home full-time \\
\hline 15 & Male & Middle manager & No & Works part-time \\
\hline
\end{tabular}

